\title{
Retos globales del feminismo frente al orden global neoliberal y conservador ${ }^{1}$
}

\author{
Global Challenges of Feminism Against \\ the Neoliberal and Conservative Global Order
}

Tomeu Sales Gelabert

Resumen: El presente texto tiene por objeto analizar las consecuencias de la globalización y la alianza entre el neoliberalismo y el conservadurismo sobre las mujeres y el feminismo. Se observa como el orden global neoliberal y conservador refuerza las desigualdades de género tanto a través de políticas públicas neoliberales como a través del cambio del imaginario social. La transformación global de la política y lo político requiere una rearticulación en clave global del feminismo. Las estrategias han ido en dos líneas: una de orden político-económico y otra de orden jurídico-normativo. Se analizarán los puntos en común de ambas estrategias y sus principales divergencias. Se defenderá la necesidad de articular un feminismo global y anti-neoliberal.

Palabras clave: feminismo, orden neoliberal, conservadurismo, globalización y feminismo neoliberal.

\begin{abstract}
The present text aims to analyse the consequences of globalization and the alliance between neoliberalism and conservatism on women and feminism. It is observed how this neoliberal and conservative global order reinforces gender inequalities both through neoliberal public policies and through the change of the social imaginary. The global transformation of politics and politics requires a global rearticulation of feminism. The strategies have gone in two lines: one of political-economic order and another of legal-normative order. The points in common of both strategies and their main divergences will be analysed. It will defence the need to articulate a global and anti-neoliberal.
\end{abstract}

Key words: Feminism, Neoliberal order, Conservatism, Globalization, Neoliberal feminism.

\section{INTRODUCCIÓN}

En tiempos convulsos, la tarea de repensar las transformaciones de lo político y la política, así como la conexión entre teoría y práctica se convierten en una necesidad. En este sentido, pretendemos reflexionar sobre la relación entre el neoliberalismo y feminismo. Los dos términos no tienen una significación unívoca, por tan-

\footnotetext{
${ }^{1}$ Esta investigación ha contado con el apoyo del Proyecto Esfera Pública y Sujetos Emergentes (FFI201675603-R, AEI/FEDER, UE).
} 
to, han de matizarse, definirse y cuestionarse. De hecho, uno de los grandes retos teóricos para visibilizar las transformaciones y traslaciones del poder, lo político y la política se halla en la redefinición del marco, cuestionando los esquemas teóricos hegemónicos. En este sentido, una mirada de género o desde la posición que tiene las mujeres en el proceso de globalización neoliberal permite tener una perspectiva diferente de las exclusiones, invisibilizaciones, dominaciones y explotaciones que este proceso sociopolítico ha supuesto. Relacionada con esta cuestión aparece otra cuestión candente: ¿Cómo se articulan las demandas y reivindicaciones de las mujeres? Se trata de analizar hasta qué punto la globalización neoliberal ha condicionado el feminismo, ha penetrado en él y ha determinado el marco de reivindicaciones feministas. En esta línea, se pueden leer una serie de debates actuales sobre la aparición de un «feminismo neoliberal» (Rottenberg, 2014), o hasta qué punto el feminismo ha sido cooptado por el «imaginario social y político» neoliberal (Fraser, 2015, 2017).

El objetivo es analizar las consecuencias de la globalización y la santa alianza entre el neoliberalismo y el conservadurismo sobre las mujeres y el feminismo. Se analizará la globalización como un cambio de orden social, político y económico, incidiendo en su versión actual, neoliberal y conservadora. El orden global neoliberal y conservador ha reforzado las desigualdades de género tanto a través de políticas públicas neoliberales como a través del cambio del imaginario social; de «razón normativa» (Brown, 2016: 35). En este sentido, apostamos por una concepción bidimensional del neoliberalismo: como políticas públicas y como nuevo imaginario social y político. Tanto las políticas económicas de privatización, desregulación, liberalización, financiarización, como la mercantilización de los sujetos, instituciones y relaciones sociales han reforzado la posición subordinada de las mujeres en la estructura social. Ello se observa con las «soluciones neoliberales» basadas en políticas de austeridad que han producido una pérdida de derechos de ciudadanía de las mujeres, una precarización del mercado de trabajo segmentado, un vaciamiento de derechos sociales y económicos consolidados, una mercantilización del propio cuerpo y la capacidad reproductora de las mujeres, y la privatización, familiarización y re-feminización de los trabajos de cuidados (Alcañiz, Monteiro, 2016: 42). Estas políticas, que algunas han llamado "políticas austericidas» (Gálvez, 2013: 82), se han tomado desde una perspectiva ciega al género aumentado la vulnerabilidad y precariedad de las mujeres.

Todo ello impulsa a la necesidad de repensar la lucha por la emancipación de la mujer en las nuevas coordenadas. La transformación global de la política y lo político requiere una rearticulación en clave global del feminismo. En este sentido las estrategias han ido en dos líneas; una de orden político-económico y otra de orden jurídico-normativo. La primera, apuesta por una redefinición ampliada del capitalismo como orden económico, social y político (Fraser, 2014, 2015). La segunda, apuesta por la redefinición de los derechos de las mujeres como derechos humanos (Jaggar, 2001, Maquieira, 2006, Guerra, 2014). La primera ha conducido a la aparición de un feminismo anticapitalista, mientras que la segunda ha conducido a un feminismo institucionalizado transnacional. El primero ha acusado al feminismo en general de haber sido cooptado por el neoliberalismo, mientras que el segundo sigue depositando gran confianza en las instituciones internacionales y 
trasnacionales (CEDAW, Conferencias Mundiales sobre las mujeres, Comisión de los derechos de la Mujer e Igualdad de enero del Parlamento Europeo, etc.) como formas de visibilizar los derechos civiles y políticos de las mujeres, y al mismo tiempo crear mecanismos legales contra las discriminaciones de género. En algunos momentos, ambas estrategias parece que van de la mano y en otras parece que se bifurcan. Se analizarán los puntos en común y las principales divergencias entre ambas. Destacar que tanto una como otra pecan de etnocentrismo. Se concluirá con la necesidad de articular un feminismo global, antineoliberal, partiendo de la base de que hay muchas maneras de concebir, ser y de actuar de las mujeres.

\section{GLOBALIZACIÓN NEOLIBERAL Y CONSERVADORA}

Definir la globalización de entrada no es un ejercicio ni fácil ni simple, debido básicamente a la multitud de definiciones que se han hecho. Se trata de un concepto sintético, que engloba una serie de transformaciones sociopolíticas interrelacionadas que se dan a finales de la década de los 70 y principios de los 80 (y esto ya se puede problematizar), caracterizadas por un proceso de integración de mercados de capital y mercancías a nivel transnacional, posibilitado por cambios tecnológicos y que supone una reestructuración del poder de los Estado-nación. Muchas son las cuestiones que deja sin responder esta definición básica y procedimental de la globalización. Lo que aquí interesa es que la fase de expansión de estos procesos coincide en el tiempo con la aparición del neoliberalismo. De hecho, neoliberalismo y globalización se han tomado como sinónimos. Entendemos por neoliberalismo tanto la aplicación de una serie de políticas públicas como un nuevo imaginario social y político que se ha tornado hegemónico. Se trata de una concepción bidimensional del neoliberalismo que evita una visión reduccionista, e importante para hacer un análisis de género del mismo. El neoliberalismo sería un conjunto de políticas públicas y económicas, pero al mismo tiempo implicaría un cambio de normatividad social; un conjunto de normas y valores sociales que generan y mantienen el consentimiento/hegemonía respecto a las relaciones de poder y sus asimetrías. En este sentido, el neoliberalismo se asemeja a una ideología, en el sentido marxista del término de falsa consciencia de la realidad que tiene una intencionalidad básica: mantener la subordinación de los dominados a través de políticas de redefinición del marco. Otras perspectivas, siguiendo un análisis foucaultiano del neoliberalismo, hablan de "razón neoliberal", "normatividad social" o "racionalidad política", en el sentido de que se trata de una nueva forma de concebir el individuo y las relaciones sociales, el ciudadano, el mercado, el Estado, la soberanía y la democracia.

Con una concepción bidimensional del neoliberalismo aparece el problema genealógico; datar o concretar su aparición. Los que definen el neoliberalismo como un conjunto de políticas públicas, sostienen que estas aparecen a lo largo de la década de los 70 como forma de revertir la tasa de ganancia del capital que a lo largo de la década de los 60 fue languideciendo y que en los primeros años de la década de los 70 se estructuró como una crisis clásica de sobreproducción del capitalismo (Harvey, 2005). En este sentido, a principio de la década de los 70 se apli- 
can en una serie de países y ciudades un conjunto de políticas de privatización, remercantilización, liberalización, financiarización, reducciones de políticas públicas sociales, reducción de la intervención del Estado en el mercado, que minan los mecanismos de sostenimiento y solidaridad social entendidos como derechos sociales de ciudadanía, conseguidos a lo largo de las luchas sociales del movimiento obrero después de la II Guerra Mundial. Dichas políticas públicas de desmantelamiento parcial del Estado interventor y social se activaron para reestructurar la tasa de ganancia de las empresas. Se pusieron en marcha una serie de políticas macroeconómicas de apertura de mercados globales de capital y de mercancías, no de mano de obra, y a nivel interno se llevaron a cabo políticas monetaristas de contención de la inflación para blindar los derechos de propiedad frente a los derechos sociales. La tasa de desempleo se disparó y se generó todo un movimiento desde el poder para acabar con la organización del movimiento obrero a través de su fragmentación, represión policial, debilitamiento del margen de concertación sindical de los convenios colectivos, etc. Estas políticas que se experimentaron en países bajo gobiernos no democráticos y que llevaban tiempo larvándose a nivel intelectual y académico primero por Von Mises y M. Friedman, y después por F. Hayek, calaron pronto en la nueva derecha que tanto M. Thatcher como R. Reagan llevaron al poder a finales de la década de los 70 y principios de los 80 .

El desmantelamiento progresivo de los derechos sociales de ciudadanía y de las políticas económicas keynesianas basadas en la intervención pública para garantizar el pleno empleo, fueron acompañadas por la resignificación del imaginario social y político apelando a la defensa de la libertad de elección, la responsabilidad de los individuos, la privatización de los problemas sociopolítico-estructurales y reclamando a la familia como «unida básica y natural de la reproducción». La apelación a la familia se sostiene sobre un modelo muy concreto de: división genérica del trabajo familiar, de despolitización de las relaciones intra-familiares amparadas bajo la égida de lo privado-íntimo y la aceptación de determinadas relaciones de poder intra-familiares que mantienen a la mujer en una posición de inferioridad, subordinación y explotación. Dicha estrategia invocó la clásica argucia de la «naturalización» de las relaciones asimétricas de poder entre las mujeres y los hombres.

Tal como recuerda W. Brown, esta concepción conservadora y naturalizada de la familia se halla en adalides del neoliberalismo como M. Friedman y M. Thatcher que en una famosa alocución declaró:

«No hay tal cosa como la sociedad. Lo que existe son hombre y mujeres individuales... [y añadió] y sus familias». (Brown, 2016: 134)

Esta concepción de la familia no niega el individualismo neoliberal que entiende que el individuo es libre (entendiendo la libertad en sentido negativo y no institucional) y responsable, sino que forma parte de su visión esencial, ya que hace reposar esta ficción del individuo sobre la estructura de relaciones asimétricas de género. Estructura patriarcal que le permite justificar y atemperar el desmantelamiento de las políticas públicas sociales asignando a las familias, léase a las mujeres, aquellas tareas que el Estado hasta el momento había desarrollado como derechos 
básicos y universales de ciudadanía. Así, el neoliberalismo, aunque aparece ideológicamente como una fase de «modernización» y un barniz de «progresismo reformista», no hace sino apelar a concepciones naturalizadoras y conservadoras de la familia. En este sentido, y en otros, neoliberalismo y conservadurismo no son más que dos caras de la misma moneda. Afirmamos y compartimos diagnóstico con Wendy Brown, que el «neoliberalismo intensifica el antiguo problema de género del liberalismo» (Brown, 2016: 142), aunque «la subordinación de género a la vez se intensifica y se altera de modo fundamental» (Brown, 2016: 141). Volveremos a esta cuestión más adelante. Solo apuntar la idea de que el neoliberalismo tiene una dimensión conservadora y que refuerza la división clásica y no problematizada por el liberalismo entre esfera pública y esfera privada; la primera entendida como política y entre iguales, la segunda entendida como relaciones entre desiguales por naturaleza.

Siguiendo la tesis de W. Streeck el capitalismo entró en una crisis en la década de los 70 , que ha tenido diferentes configuraciones como crisis de

«la inflación global de los 70, la explosión de la deuda pública en la década de los 80 y el rápido aumento del endeudamiento privado durante la década siguiente, que dio lugar al colapso de los mercados financieros en 2008» (Streeck, 2017: 31)

Una onda larga de crisis del capitalismo que ha terminado con la crisis sistémica; es decir, económica, política y social, que se desató a partir de 2008. Período de crisis en que el Estado y las políticas públicas han transformado paulatinamente el Estado desde uno fiscal en los años 70, pasando por un Estado deudor con el afianzamiento del «sector financiero dinámico y cada vez más globalizado» (Streeck, 2017: 32), a un Estado consolidador en la década de los 90 . Estado centrado en la consolidación fiscal y la reducción de servicios, prestaciones y transferencias públicas. En esta fase, el socialiberalismo de la tercera vía pregonada por T. Blair y A. Giddens y seguido de cerca por B. Clinton y otros mandatarios europeos como G. Schroeder, apelaron al Workfare y a la idea de reducir la presión fiscal. Por el camino se perdió el ánimo redistribuidor de la política fiscal y la protección de los derechos sociales de ciudadanía, universales y no condicionados.

Esta estrategia política no solo tuvo costes sociales y políticos en el sentido de pérdida de derechos, sino que generó el sustrato para la aparición de la siguiente crisis: la crisis de 2008. La estrategia del Estado consolidador y la reducción de políticas públicas obligó a los individuos a hacerse cargo de los problemas sociales estructurales y esto fue posible a través del endeudamiento privado y la permisividad de la financiarización de la misma. Financiarización y titularización de la deuda privada que generó un espectacular apalancamiento de los beneficios del capital financiero, que aceleró su globalización y que forjó una burbuja económica. Al destaparse la ficción del empaquetamiento bancario de deuda vendida, se descubrió que gran parte del sector financiero internacionalizado poseía activos sin valor. La historia siguiente ya se conoce. El Estado socializó de forma selectiva las pérdidas privadas de las entidades financieras, con lo cual aumentó el déficit público, y abrió la puerta al "Estado austeridad". Se pusieron en marcha políticas de austeridad basadas en políticas fiscales regresivas y se redujeron, desmantelaron o eliminaron determina- 
das políticas públicas sociales, para contener el gasto social y sufragar el gasto financiero derivado de la socialización de la deuda de las instituciones financieras.

Estas dinámicas de austeridad se implementaron a nivel global y tuvieron un impacto de género claro en muchos sentidos (Gálvez, 2013: 82, 87): 1) reprivatización, familiarización y feminización de las tareas de cuidado; 2) condicionamiento de los derechos de ciudadanía a la participación del ciudadano al trabajo considerado como "normal": remunerado, a tiempo completo e indefinido, trabajo claramente masculino; 3) obligación de participación en el mercado de trabajo público (interés por elevar la tasa de población activa de las mujeres) debido a la pérdida de poder adquisitivo de los salarios de los "maridos sustentadores"; 4) precarización y segmentación del mercado de trabajo femenino. Segmentación del mercado de trabajo en dos grandes mercados en razón de género: un mercado de trabajo primario típicamente masculino y un mercado de trabajo típicamente femenino con formas contractuales más inestables, parciales, menor remuneración y por tanto con generación de menos derechos de ciudadanía, en el sentido indicado más arriba (Alcañiz, Monteiro, 2017: 54). De hecho, si en un primer momento de la crisis, hubo una pérdida de trabajos claramente masculinos y el mantenimiento tanto de la tasa de actividad como de ocupación de las mujeres, en una segunda fase de la crisis, los trabajos feminizados fueron los que recibieron la peor parte, por ser trabajos más precarios y relacionados con el sector público y las políticas sociales (Castaño, 2015:18). Así, el giro neoliberal de las políticas públicas no solo ha tenido consecuencias de clase, afectando a las clases trabajadoras y populares, sino también a las mujeres, sobre todo en su versión de políticas de la austeridad. El subtexto de género es claro y las consecuencias políticas, sociales y económicas de las políticas neoliberales hacia las mujeres no pueden ser peores.

\section{¿NEOLIBERALIZACIÓN DEL FEMINISMO?}

En este sentido, y viendo el proyecto neoliberal como reestructurador de políticas públicas, se observan dos cuestiones desde la perspectiva de las mujeres: se trata de un proyecto global, aunque con concreciones en políticas públicas y justificaciones locales, y de cuño claramente conservador. Por todo ello, y en este sentido, un «feminismo neoliberal» no es más que un oxímoron en sentido normativo. No obstante, ha aparecido un análisis fenomenológico de la neoliberalización del feminismo que acuña directamente el término «feminismo neoliberal» (Rottenberg, 2014) para caracterizar estas nuevas dinámicas de cooptación neoliberal de los discursos y prácticas feministas 2 .

\footnotetext{
2 Analizando el neoliberalismo como una nueva racionalidad, C. Rottenberg sostiene que ha emergido en EEUU un «feminismo neoliberal» y que negarlo incapacita el análisis crítico sobre «la clase de trabajo cultural que emerge con el feminismo neoliberal» (Rottenberg, 2014: 430). La estrategia discursiva se basa en la apropiación del discurso de feminismo liberal, vaciarlo de contenido, y proyectar una serie de propuestas que van en la línea, no de criticar, sino de reforzar la racionalidad neoliberal (Rottenberg, 2014: 419). Así, la racionalidad neoliberal consigue la neutralización de la crítica feminista a las democracias liberales y se convierte en instrumento de legitimación de la estrategia imperialista norteamericana, ya que entiende que la igualdad de género solo se puede conseguir en democracias liberales como la norteamericana (Rottenberg, 2014: 432). Este feminismo neoliberal se articula de la mano de mujeres de éxito (representan menos del $1 \%$ de las mujeres
} 
Para superar este dilema entre un análisis normativo y uno fáctico del feminismo, autoras como N. Fraser acuñan el término «neoliberalismo progresista», ya que el neoliberalismo con la retórica de la «reforma» y la «modernización» puede cubrirse con el barniz de progresismo, tal como en la década de los 90 hizo el social-liberalismo de la tercera vía. Para Fraser:

«"el neoliberalismo progresista" es una amalgama de trucados ideales de emancipación y formas letales de financiarización». (Fraser, 2017: 3)

Precisamente esta amalgama es la que perdió y rechazaron los electores al castigar a H. Clinton. Si bien, una gran parte de la izquierda académica y alternativa acepta dicho diagnóstico, se muestran muy reacios a aceptar otra tesis sostenida en el mismo texto por parte de N. Fraser en que define el neoliberalismo progresista como

«una alianza de las corrientes principales de los nuevos movimientos sociales (feminismo, antirracismo, multiculturalismo y derechos de los LGBTQ), por un lado, y, por el otro, sectores de negocios de gama alta "simbólica" y sectores servicios (Wall Street, Silicon Valley y Hollywood). En esta alianza, las fuerzas progresistas se han unido efectivamente con las fuerzas del capitalismo cognitivo, especialmente la financiarización.» (Fraser, 2017: 2)

Básicamente, Fraser defiende una tesis que ya hace un tiempo está elaborando $^{3}$ y que ha sido fuertemente contestada (Shild, 2016; Brenner, 2017). Una tesis que insiste en que gran parte de los novísimos movimientos sociales de carácter emancipador han sido cooptados por el neoliberalismo, con lo cual por una parte se han desactivado políticamente y por otra han servido de instrumento discursivo para legitimar las políticas públicas neoliberales ${ }^{4}$. La discusión entre Johanna Brenner y Nancy Fraser es ilustrativa al respeto. Brenner critica a Fraser por caracterización genérica que hace del feminismo y por la idea de su cooptado por el neoliberalismo. Enumera un conjunto de reivindicaciones feministas locales y concretas que difícilmente pueden considerarse como neoliberales. Expresan críticas y propuestas contrarias a dinámica de recorte de derechos sociales y políticos, muestran como

norteamericanas) que tomando los objetivos del feminismo liberal de «igualdad de género, oportunidad, libre decisión» (Rottenberg, 2014: 421) no proponen cursos de acción colectivos y críticos respeto a las estructuras de poder que impiden la obtención de dichos objetivos, sino un cambio interior de las propias mujeres. La transmutación del feminismo liberal en neoliberal radica en un «cambio de énfasis: desde el intento de alterar las presiones sociales, hacia los espacios de interiorización afectiva, que requieren una constante automonitorización» (Rottenberg, 2014: 424). Se propone una «interiorización de la revolución», apoyarse en su carrera, superar la brecha de la ambición por el liderazgo y la busca personal e individual de un «feliz balance ecuánime entre trabajo y familia» (Rottenberg, 2014: 427). Se apuesta por la individualización e interiorización de la responsabilidad de las situaciones de desigualdad de las mujeres, la desaparición de la crítica a las estructuras sociales de poder y la imposibilidad de generar un sujeto colectivo. Se trata un proceso de sujetivización empresarial de la mujer y del feminismo, funcional al proyecto neoliberal e imperialista.

3 Apareció en el texto de 2008 titulado El feminismo, el capitalismo y la astucia de la bistoria.

${ }^{4}$ Rottenberg no acepta la «culpabilización» que N. Fraser atribuye al feminismo en la articulación de un «neoliberalismo progresista», aunque reconoce que, gracias a su trabajo, ha emergido la reflexión crítica sobre este nuevo feminismo neoliberal (Rottenberg, 2014: 421). 
estos afectan especialmente a las mujeres y proponen vías de reconocimiento de nuevos derechos de ciudadanía de forma universal y no condicionada. Así, Brenner propone diferenciar entre un "feminismo liberal" y un feminismo que ella califica "del bienestar social". Un feminismo institucional y vindicador de derechos iguales e individuales que «busca un estado expansivo y activo que aborde los problemas de las mujeres trabajadoras, que alivie la carga de la "doble jornada", [...] ganar estas demandas exigía una confrontación con el poder de la clase capitalista» (Brenner y Fraser, 2017:4). En este sentido, según Brenner, el feminismo «no fue cooptado, sino políticamente marginado» (Brenner, Fraser, 2017: 4).

Por su parte, Fraser responde que su tesis no va en la línea de desacreditar ni el trabajo del feminismo institucional, que Brenner llama "del bienestar social", ni de caricaturizar los diferentes movimientos feministas locales que enumera, a los cuales admira y reconoce como movimientos sociales críticos. Para Fraser, cuando ella habla de cooptación neoliberal del feminismo se refiere a que el imaginario neoliberal ha sido asumido de forma acrítica por el feminismo, con lo cual sus reivindicaciones han dejado de ser críticas, para reforzar el estatus quo. Fraser habla de una nueva «hegemonía del progresismo neoliberal» en que ideales emancipadores esgrimidos por las feministas fungen no como elementos críticos, sino como elementos que legitiman la acumulación del capital, su financiarización y el desmantelamiento de los derechos sociales y políticos. Por ello, apuesta por generar una nueva «contra-hegemonía [que ella ve en los partidarios de B. Sanders] que en lugar de la alianza "finanziarización-y-emancipación", nos dejó entrever un nuevo bloque populista y progresista que combina la emancipación con la protección social» (Brenner, Fraser, 2017: 8).

Esta discusión entre Fraser y Brenner sobre «el neoliberalismo progresista» y la cooptación neoliberal del feminismo, que se ha extendido, está mal planteada. Brenner y Fraser hablan de cosas diferentes. Se necesita introducir alguna categoría de mediación para clarificar el debate. Mientras que Brenner muestra con ejemplos concretos como algunos movimientos feministas se estructuraron y se siguen estructurando contra las políticas públicas neoliberales, además de mostrar la importancia que tiene el feminismo institucional, Fraser habla de neoliberalismo en otro sentido. Se refiere al neoliberalismo no tanto como políticas públicas, sino como «imaginario socio-político», o lo que Brown, y Dardot y Laval, llaman "razón neoliberal" o "normatividad neoliberal", siguiendo el análisis que M. Foucault. En este sentido, si se entiende el neoliberalismo de forma bidimensional, la postura de Brenner y de Fraser no se contradicen en absoluto. Aunque gran parte del feminismo se haya posicionado en contra de las reformas de las políticas públicas neoliberales, como apunta Brenner, estas han utilizado un lenguaje y un discurso que en parte ha asumido la razón neoliberal, es decir, un concepto de individuo, de derechos, de Estado, de políticas, etc., que ha provocado que su potencial emancipador se haya diluido en los últimos años, como afirma N. Fraser. Pero para entender dicho punto, deberíamos explicar, qué se entiende por «razón o racionalidad o normatividad neoliberal». 


\section{LA NORMATIVIDAD NEOLIBERAL}

En la actualidad ha aparecido una amplia literatura que analiza el neoliberalismo no como una continuación del liberalismo clásico, ni como una ideología destructora de normas, sino como una nueva forma de racionalidad que implica una reestructuración de la concepción del sujeto, del Estado, de la ciudadanía y de la democracia. En este sentido, cabe destacar las contribuciones desarrolladas por W. Brown, Ch. Laval y P. Dardot, y la de W. Davies. Los tres primeros siguiendo y reactualizando los análisis de Foucault sobre el neoliberalismo de finales de la década de los 70, mientras que W. Davies sigue una estrategia neo-weberiana, que entiende el neoliberalismo como una especie de "nuevo espíritu del capitalismo", siguiendo las tesis de L. Boltanski y E. Chiapello. Voy a reelaborar brevemente las tesis de los cuatro autores, para captar su aportación.

W. Davies defiende que las últimas propuestas de políticas de austeridad emprendidas a nivel global, pero sobre todo en Europa, muestran la necesidad de ser más sutiles a la hora de hablar del neoliberalismo. Defiende diferenciar tres grandes fases del neoliberalismo. Una primera que llama "neoliberalismo combativo", que se desarrolla entre 1979 y 1989, cuyos representantes políticos fueron M. Thatcher y R. Reagan; una segunda fase que llama "neoliberalismo normativo", que comprendería el período histórico que va la implosión de la U. Soviética hasta 2008, en que los representantes más destacados serían los social-liberales defensores de la tercera vía; y una última fase que caracteriza como "neoliberalismo punitivo", que representaría la nueva fase post-crisis del 2008. Las diferencias entre estas fases son importantes.

La fase del neoliberalismo combativo basada en la tesis de Von Mises y Hayek pretendía enmarcar el debate entre liberalismo o totalitarismo, para desacreditar y fundamentar la irracionalidad tanto de la lógica socialdemócrata clásica como del socialismo real. Se proponían una serie de políticas públicas de mercantilización como políticas de liberalización, para reestablecer la racionalidad, la libertad y la responsabilidad en las democracias liberales. La coherencia del neoliberalismo se establece como «oposición combativa al socialismo, cuya destrucción, tanto internacional como nacional proporcionaba su telos motivadon» (Davies, 2016: 135). Una vez desaparecido el enemigo principal y desactivado el socialismo como lógica política, el neoliberalismo dejó de ser destructivo y crítico para convertirse en una nueva lógica de construcción de normas sociales y políticas bajo el «criterio de la competencia» (Davies, 2016: 136). Se naturalizaban las desigualdades y se justificaban ideológicamente como fruto de la competencia entre individuos, libres y responsables, con lo cual se pudo al mismo tiempo justificar, bajo la rúbrica de la "modernización", "racionalización" y la "gobernanza" los recortes de las políticas públicas sociales y de bienestar de la mano de los gobiernos social-liberales. Así, se da una inversión de los valores e ideales de igualdad, libertad, responsabilidad y equidad que se leen ahora bajo el prisma de la eficiencia, la competitividad y la efectividad (Davies, 2016: 137). La lógica entre ganadores y perdedores de la globalización fue naturalizada e interiorizada, tanto por parte de los gobiernos como por parte de los individuos, que se responsabilizaban de sus fracasos sociales y profesionales. 
La última fase del neoliberalismo, que Davies llama "punitivo", es la fase actual que viene representada por la aplicación de políticas de austeridad, donde una vez demostrada la falsedad interesada de los ránquines y agencias de calificación y la imposibilidad de la auto-organización de los mercados como distribuidores eficientes de bienes y de recursos, se activa una lógica de moralización y culpabilización de los perdedores, para justificar las políticas de austeridad como políticas punitivas. La discusión de la racionalidad de las políticas de austeridad ya no es objeto de disputa. Así, los recortes de derechos sociales y políticos aparecen como medidas "merecidas" e incuestionables. En esta nueva fase del neoliberalismo, el recurso a la discusión pública y razonada ha perdido sentido y efectividad ${ }^{5}$, quedando solo la «repetición» de argumentos como si estos fueran dogmas, y las medidas de recortes aparecen como una «cierta forma de venganza» (Davies, 2016: 141) de los ganadores frente a los vencidos o enemigos. En este sentido, se caracteriza esta nueva fase del neoliberalismo como "neoliberalismo punitivo".

Por otro lado, Laval, Dardot y Brown insisten en la vía emprendida por Foucault de caracterizar el neoliberalismo como una novedad que rompe con el liberalismo clásico y que implica una nueva forma de "gubernamentabilidad" por la cual la lógica central es la de regir la conducta de los hombres. En este sentido, el neoliberalismo entendido como

«racionalidad neoliberal tiene como característica principal la generalización de la competencia como norma de conducta y de la empresa como modelo de subjetivación.» (Laval y Dardot, 2013: 15)

Esta nueva normatividad social presenta un tipo de sociedad entendida como un mercado competitivo, en que el sujeto se define como capital que ha de auto-valorizarse en un medio competitivo, y el Estado como una empresa más que debe valorizarse. El gobierno se transforma en un gobierno gerencial, el derecho privado substituye al derecho público, y el sujeto se convierte en un sujeto neoliberal o empresarial.

«De esta primacía absoluta del derecho privado resulta un vaciamiento progresivo de todas las categorías del derecho público que va en la dirección, no de su derogación formal, sino de una desactivación de su validez operativa. El Estado está obligado, en adelante, a contemplarse a sí mismo como una empresa, tanto en su funcionamiento interno como en su relación con otros Estados.» (Laval y Dardot, 2013: 384)

El Estado de derecho se transforma en un Estado competitivo y empresarial. Por otro lado, el sujeto neoliberal o empresarial es entendido como un ser activo, unitario, que compite entre otros. Interioriza el riesgo de sus acciones como

${ }^{5}$ Este diagnóstico presenta un reto a determinadas teorías políticas normativas que defienden la democracia deliberativa y el reforzamiento de la esfera pública como fiscalizadora y controladora del poder político. Si bien formalmente sigue existiendo una esfera pública, la opinión pública y las dinámicas que en ella se dan, dejan de ser racionales y razonables para ser lógicas de repetición basadas en las correlaciones de poder de los agentes. La distancia entre lo fáctico y lo normativo se amplía, y se requiere repensar nuevas instancias de mediación. 
inversiones, ya que no tienen un Estado que lo pueda sostener. Se rige por la efectividad de su acción, entregado al cambio, mejoramiento y aprendizaje continuo como forma de revalorizarse. Busca sobrevivir en un mundo de competencia feroz, que modifica su deseo, ahora basado en un deseo de rendimiento continuado y que exalta los valores del éxito, la fuerza, el combate y el vigor. Así,

«el individuo ya no debe considerarse a sí mismo como un trabajador, sino como una empresa que vende un servicio en un mercado [...] porque toda la actividad del individuo es concebida como un proceso de valorización de sí.» (Laval, Dardot, 2013: 339-340)

En este sentido, Laval y Dardot analizan el neoliberalismo como una nueva forma de gubernamentalidad o gobierno a través del control de la conducta de los individuos que ha producido un nuevo "imaginario social y político", redefiniendo tanto los individuos, como el papel del Estado, de la política, el derecho y la democracia. Una nueva concepción empresarial del sujeto y del Estado que, aunque mantenga las formas y los conceptos de la anterior cosmovisión, ha desactivado su potencialidad crítica frente a la dinámica competencial del mercado. En este sentido, los autores hablan de una "estrategia sin estratego" para caracterizar esta nueva gubernamentalidad neoliberal, lo cual dificulta la identificación de los responsables de la misma, los ganadores de la misma, las lógicas de explotación y extracción de plusvalía que implican y quien se las apropia. Además, dificulta la posibilidad de pensar si quiera de salir de esta nueva razón neoliberal (Laval y Dardot, 2013: 395). No obstante, lo que interesa aquí es observar el subtexto de género de esta nueva razón neoliberal, que en el caso de los autores citados no aparece explicitada.

Quien sí centra relativamente su interés en el subtexto de género de esta nueva racionalidad es W. Brown. Siguiendo a Foucault de cerca en su análisis del neoliberalismo, ella sostiene que se hace necesario reactualizar su análisis, ya que Foucault teorizó sobre el neoliberalismo a finales de la década de los 70 y no pudo observar ni calibrar la nueva dinámica financiarizada que el capitalismo emprendió en los años 90. Además, acusa al análisis de Foucault de ignorar que frente al homo oeconómico que el liberalismo impulsó y que el neoliberalismo reelaboró, existía la figura del homo politicus o ciudadano, como sujeto de derechos y capaz de soberanía sobre sí mismo, y su anti-marxismo (Brown, 2015: 96). Es lo que Brown llama el problema de la "“formulación de lo político", una formulación que, en buena medida, está limitada a los términos (irónicamente centrados en el Estado) de "soberanía” y "juridicismo"» (Brown, 2015: 94). Sostiene que sin tener en cuenta la separación de esferas que supuso el liberalismo clásico entre el ámbito político y el ámbito económico, ilustrado con la figura del ciudadano y el burgués, no se pueden calibrar las corrientes emancipadoras y democráticas basadas en la justicia, la igualdad, la vindicación de derechos y la soberanía popular del pensamiento político moderno. Partiendo de Foucault y criticando sus déficits, Brown pretende mostrar como «la razón neoliberal genera una explicación rica de la des-democratización neoliberal» (Brown, 2015: 99). 
A diferencia de Laval y Dardot, Brown muestra las incoherencias y los problemas de género que provoca la concepción del sujeto neoliberal como autovalorizador de capital en un ambiente de competitividad, que ella llama la formulación del "homo oeconomicus neoliberal". La ficción del homo oeconomicus neoliberal es incapaz de reproducirse y de sostenerse por sí mismo, con lo cual implica y al mismo tiempo invisibiliza una esfera de trabajos de cuidados que necesita, presupone, pero no explicita. Y esta estructura de provisión de cuidados tiene un subtexto de género, por ser las mujeres las que tradicionalmente han producido estos cuidados. Con lo cual, o bien la ficción del homo oeconomicus solo es aplicable a los varones o bien si se aplica de forma universal genera una doble explotación de las mujeres: por ser sujetos que se valoran a sí mismos como capitales que se invierten para valorizarse y como no-sujetos, irracionales y proveedores de cuidados. Brown expone de forma clara cuales son las vías que quedan a las mujeres cuando el homo oeconomicus neoliberal se convierte en la norma social y política rectora:

«Ya sea que las mujeres alineen su conducta con esta verdad, convirtiéndose así en homo oeconomicus, en cuyo caso el mundo se vuelve inhabitable, ya sea que las actividades de las mujeres y su comportamiento como fémina domestica se conserve como el pegamento no reconocido de un mundo cuyo principio rector no puede mantenerlo unido, en cuyo caso las mujeres ocupan su antiguo lugar como sostenes y complementos no reconocidos de cuidado para otros». (Brown, 2015: 141)

Si bien Brown realiza un análisis de género y feminista sobre la nueva ficción del hombre oeconomicus que instituye el neoliberalismo, su tesis central es que el neoliberalismo borra las fronteras que el liberalismo clásico sostuvo entre el bomo oeconimicus y el homo politicus; es decir, entre el burgués y el ciudadano. A ojos de Brown, el neoliberalismo ha roto con la separación de esferas y ha impuesto un único patrón de conducta tanto en la esfera económica, como política y social: el sujeto neoliberal entendido como capital financiero que se auto-valora por sí mismo, en un ambiente de competitividad y responsable individual de sus acciones. Se ha producido una corrosión, desmantelamiento y vaciamiento del homo politicus. Con lo cual, y aquí radica la tesis central que quiere propone Brown: el neoliberalismo entendido como una nueva forma de racionalidad ha generado un proceso de "desdemocratización" o lo que ella llama de "desaparición del demos". Formalmente seguimos viviendo en "democracias liberales", pero ha desaparecido el sujeto de dichas democracias, léase el ciudadano, y también el pueblo, entendido como el sujeto político colectivo que se auto-legisla por sí mismo a través de la soberanía popular.

En este sentido, Brown parte al igual que Laval y Dardot del análisis del neoliberalismo como nueva racionalidad que inicia Foucault, sigue caminos diferentes, pero llega a la misma conclusión: con el neoliberalismo ha aparecido una nueva normatividad y ontología social donde los sujetos, tanto colectivos como individuales, son considerados como capital que se han de valorizarse en un ambiente de competitividad, que ha vaciado de significado los conceptos del pensamiento político moderno. A nivel crítico, desde una perspectiva feminista, Brown 
solo hace un análisis de las implicaciones de género del nuevo homo oeconomicus neoliberal, sin percatarse de las críticas feministas a la ciudadanía y al homo politicus tal como emergió en la modernidad (Agra, 2011). Esta crítica es significativa, porque la solución que propone Brown para salir de la racionalidad neoliberal es la recuperación y el robustecimiento del homo políticus, solución que no superaría los problemas de la estructura patriarcal de la feminización de los trabajos de cuidados. No sería una solución feminista, sino que reforzaría el sistema de opresión, subordinación y explotación de las mujeres al excluirlas de la ciudadanía.

\section{Alternativas GLOBALES FEMINISTAS}

En este nuevo marco global neoliberal se hace necesario replantear las estrategias de acción feminista. Estas pasan por reivindicaciones globales y anti-neoliberales ${ }^{6}$. Pero a partir de aquí las estrategias se bifurcan. Una propone redefinir de forma ampliada el capitalismo y vehicular las estrategias feministas como luchas anticapitalistas. Destacamos en este sentido al feminismo marxista, de Silvia Federicci o los últimos desarrollos de N. Fraser. La otra vía es la que se articula en la reestructuración de la acción feminista a través del derecho internacional público redefiniendo los derechos de las mujeres como derechos humanos.

La vía de la redefinición ampliada del capitalismo como forma de producción y de reproducción social tiene sus antecedentes en los debates del feminismo marxista de la segunda Ola. S. Federicci y M. Rosa Dalla Costa trabajaron en esta vía para mostrar que el capitalismo no es solo un sistema social de producción de mercancías, sino que implica un sistema de reproducción. Esta invisibilización de la reproducción social es una estrategia en si misma patriarcal y se muestra en el trabajo no reconocido, ni valorado ni remunerado de las mujeres en la provisión de cuidado. Se hace necesario visibilizar la necesidad del momento de la reproducción y los trabajos de cuidados para que se dé el momento de la producción. Así, el capitalismo se basa no solo en la plusvalía o trabajo no remunerado, sino que también implica una plusvalía de género. En otros términos, D. Harvey sostiene que se ha

\footnotetext{
${ }^{6}$ Aunque las dos alternativas feministas se articulan como propuestas antineoliberales, una se presenta claramente como propuesta anticapitalista, mientras que otra solo pretende revertir la neoliberalización. En este sentido, Carlos Taibo (2011) a raíz de la crisis sistémica de 2008 propone diferenciar entre dos tipos de diagnósticos y propuestas políticas que se derivan: un diagnóstico y propuesta antineoliberal y otro anticapitalista. La primera centra su diagnóstico en la «desregulación que ha acompañado a la revolución neoliberal [...] la respuesta no puede ser otra que la que reclame la reconstrucción de la regulación perdida... y el reflotamiento de los Estados del Bienestar» (Taibo, 2011: 150). Por contra, el diagnóstico y la propuesta anticapitalista sostiene que «el capitalismo ha perdido dramáticamente los mecanismos de freno que en otros momentos le permitieron salvar la cara y entiende que, ha iniciado una deriva terminal [...] así, se inclina más bien por aguardar que el colapso del sistema abra, por fin, los ojos de buena parte de la población» (Taibo, 2011: 151). El diagnóstico antineoliberal lee la crisis sistémica como un problema de regulación y apuesta por la defensa del Estado de bienestar, garantizando zonas de interacción no mercantilistas, mientras que la propuesta anticapitalista, lee la crisis como crisis civilizatoria y apuesta por la superación del modo de producción capitalista. Se trataría de la contraposición clásica entre reformismo y acción radical, que podría utilizarse para diferenciar entre las dos formas de acción feminista global. Una apuesta por el Estado de derecho y social, con un capitalismo embridado, mientras que la segunda apuesta por la necesidad de superar dicho sistema que ha propiciado las diferentes dimensiones de la crisis.
} 
de diferenciar entre la lógica de valorización ampliada del capital y el capitalismo, como sociedad en que se incrusta dicha lógica de valorización del capital (Harvey, 2017: 22). Esta sociedad capitalista puede activar o mantener lógicas no capitalistas mientras ayuden y no cuestionen la lógica de valorización del capital. La provisión patriarcal de los trabajos de cuidados se incorpora a la lógica de capital porque permite que este se valorice sin tener que remunerar los coses sociales de la reproducción del mismo. La provisión patriarcal de los cuidados es presente en la sociedad capitalista y funcional a la lógica de valorización del capital.

Siguiendo esta línea, se sitúan los últimos desarrollos de Nancy Fraser, que defiende una concepción ampliada del capitalismo por la cual se analiza lo que ella llama las "condiciones de posibilidad de fondo", que vendrían representadas por un ámbito reproductivo, por la naturaleza y por la existencia de unos poderes públicos. Ámbitos que solo pueden garantizar la reproducción y valorización del capital a cambio de considerarse como ámbitos de interacción dados, no remunerables, ni mercantilizados. Dicho de otra manera, el capitalismo como sistema organizado de valorización ampliada del capital requiere de un «orden social institucionalizado» no mercantilizado ni recompensado (Fraser, 2014: 69). Siguiendo esta línea de la redefinición ampliada del capitalismo de la mano del feminismo marxista, la estrategia de lucha feminista es no tanto a favor de la vindicación de derechos y la defensa de un feminismo institucionalizado, sino de articular el feminismo como una lucha anticapitalista y la configuración de lo que D. Harvey llama un nuevo «humanismo revolucionario» (Harvey, 2014: 277).

La otra vía, viene representada por la defensa de los derechos de las mujeres como derechos humanos y la apelación al Estado y a los órdenes políticos y normativos transnacionales como plataforma de defensa de los derechos de las mujeres. Vía puesta en marcha a mediados de la década de los 70 con la proclamación del año internacional de la mujer, que vendría seguido por la Declaración sobre la eliminación de todas las formas de discriminación contra la mujer que aprobó la Asamblea General de la ONU en 1979 y la creación del Comité CEDAW que hace un seguimiento de la declaración por parte de los Estados miembros (Torres y Antón, 2010: 20). A esta declaración le siguieron una serie de Conferencias sobre las mujeres. En este recorrido de consolidación de los derechos de las mujeres como derechos humanos debemos destacar dos momentos significativos: la II Conferencia Mundial sobre Derechos Humanos celebrada en Viena en 1993 que expresamente reconoció: «los derechos humanos de la mujer y de la niña son parte inalienable, integrante e indivisible de los derechos humanos universales» (Torres y Antón, 2010:21); y la IV Conferencia Mundial sobre la Mujer, Acción para la igualdad, el Desarrollo y la Paz celebrada en Beijing en 1995 , en que se dieron a conocer a nivel global las demandas de las mujeres y las feministas (Maquieira, 2006: 33). Se puso en marcha la Plataforma de Acción con una serie de medidas para alcanzar la igualdad entre hombres y mujeres que ha tenido un impacto jurídico muy destacado sobre todo en Europa con la introducción del «mainstream de género» en los tratados europeos como el Tratado de Ámsterdam.

Este esfuerzo por incorporar las reivindicaciones feministas al derecho internacional público ha tenido un fuerte impacto a nivel global, ya que ha permitido la apelación al marco de los derechos humanos en los casos de vulneración local o 
estatal de los derechos de las mujeres. Además, se hizo explícito el carácter internacionalista de las reivindicaciones feministas y se elaboró una agenda feminista transnacional (Guerra, 2014: 166). Ahora bien, no deben menospreciarse las críticas que se han hecho a dicho enfoque: la limitación del impacto de dichas medidas en tanto que dichas Declaraciones y Convenios dependen de la adhesión de los Estados miembros, la no existencia de mecanismos de responsabilidad por parte de aquellos Estados miembros que permiten la vulneración de los derechos de las mujeres y las críticas al etnocentrismo "maternalista" de dicha estrategia por parte de los movimientos de mujeres y feministas del "Sur". En este sentido, muchos de los Estados miembros que han reconocido dichos convenios o declaraciones, han formulado al respecto una serie de "reservas formales" sobre determinados artículos. La mayoría de los cuales hacen referencia a la familia y a los derechos sexuales y reproductivos de las mijeres. Es el caso de la CEDAW que, aunque ratificado por 179 Estados, 53 de los cuales han formulado reservar respecto a determinados artículos (Maquieira, 2006: 58). Así, su impacto práctico sobre la vida y el bienestar de las mujeres es limitado. Crece la sospecha de que estas Declaraciones no dejan de ser declaraciones formales, al no establecer mecanismos que obliguen a los Estados a cumplir sus compromisos, sino que también pueden funcionar como mecanismos de legitimación de determinados Estados que permiten la vulneración de los derechos de las mujeres.

Más allá de estas limitaciones, la vía del reconocimiento de los derechos de las mujeres como derechos humanos, tuvo un amplio recorrido desde mediados de la década de los 90 hasta el principio la primera década del siglo XXI. En la actualidad, se ha perdido el entusiasmo inicial, sobre todo después de la crisis del 2008. No se ha convertido en una vía muerta, pero si en una vía que, aunque tiene sus virtudes, no deja de ser una vía moral y no tanto política de vindicación de derechos. Las transformaciones del Estado y del derecho acaecidas de forma subrepticia por parte del neoliberalismo hegemónico han hecho que dicha vía de reconocimiento institucional de derechos haya perdido fuelle y esperanza.

\section{CONCLUSIÓN}

Si analizamos la globalización neoliberal y en concreto el neoliberalismo desde una perspectiva bidimensional, es decir, como políticas públicas y como establecimiento de un nuevo "imaginario social y político", se observa que este ha tenido un fuerte impacto sobre las mujeres y sobre sus reivindicaciones. Un análisis del neoliberalismo muestra que este es conservador y patriarcal, ya que se fundamente en una visión del individuo, la familia, la sociedad, el derecho y el Estado que invisibiliza las tareas que tradicionalmente han desarrollado las mujeres, al mismo tiempo que promueve una serie de políticas públicas que producen una re-privatización de las tareas de cuidados, la familiarización y la feminización de las mismas. Por ello, se hace necesario rearticular las reivindicaciones feministas como reivindicaciones globales y antineoliberales. Las estrategias pueden pasar por rearticular el feminismo como un movimiento anticapitalista o bien por la articulación trasnacional de la defensa del Estado y la ciudadanía, entendida esta como sujeto de derechos que 
tiene capacidad de auto-legislarse. Esta última estrategia coincide con la estrategia puesta en marcha por el feminismo transnacional de defensa de los derechos de las mujeres como derechos humanos. Debe alertarse que esta estrategia ha de ser consciente de las modificaciones que el Estado ha sufrido con su neoliberalización, y como dicha neoliberalización no solo dificulta la protección de los derechos de las mujeres, sino que ha vaciado de contenido la idea de derechos y de ciudadanía. Con lo cual, esta estrategia, aunque bien intencionada, puede producir el efecto contrario, de legitimar el Estado neoliberal, sin que varíe un ápice la posición de vulnerabilidad de las mujeres en su propio territorio.

En este sentido, los debates sobre el "feminismo neoliberal" ocuparán las preocupaciones feministas en los próximos años. Si bien es cierto que ninguna reivindicación feminista se auto-definirá como feminismo neoliberal, ya que como hemos expuesto no deja de ser un oxímoron, sí que determinadas estrategias pueden ir en la línea, de reforzar la neoliberalización del individuo, la sociedad y el Estado. Neoliberalización que no hace sino debilitar el papel de la ciudadanía y la democracia. En estos momentos está en juego la ciudadanía y la democracia, y las organizaciones feministas que articulan las reivindicaciones de las mujeres son conscientes de ello. La proclamación formal de determinados derechos puede que utilice las mujeres como señuelos o como objetos cuyo interés último no sea la defensa de los derechos e intereses de las mujeres o la conversión de estas en sujeto en vez de objeto, como tradicionalmente ha sido consideradas (Fraisse, 2016). En este sentido, debemos estar atento al impacto del neoliberalismo en nuestras vidas, tener presente como afectan a las mujeres, y articular potentes reivindicaciones anti-neoliberales.

\section{REFERENCIAS BIBLIOGRÁFICAS}

Agra, M. X. (2011). "Ciudadanía en un mundo desigual”, en Actas XVIII Jornadas Internacionales de Investigación Interdisciplinar. Feminismos y desequilibrios en el mundo actual, Madrid: Instituto de Estudios de la Mujer-Ediciones de la Universidad Autónoma de Madrid, pp. 9-31.

Alcañiz, M., Monteiro, R. (2016). "She-austerity. Precariedad y desigualdad laboral de las mujeres en el Sur de Europa", en Convergencia. Revista de Ciencias sociales, 72, pp. 39-68. México: Universidad Autónoma del Estado de México

Brown, W. (2016). El pueblo sin atributos. La secreta revolución del neoliberalismo. Barcelona: Malpaso.

Laval, Ch., Dardot, P. (2013). La nueva razón del mundo. Barcelona: Gedisa.

Davies, W., (2013). "El nuevo neoliberalismo", New Left Review, 101, pp. 129-143. Madrid: Editorial Akal.

Federicci, S. (2013). Revolución del punto cero. Trabajo doméstico, reproducción y luchas feministas, Madrid: Traficantes de sueños.

Fraisse, G. (2016). Los excesos del género, Madrid: Cátedra.

Fraser, N. (2015). Fortunas del feminismo. Del capitalismo gestionado por el Estado a la crisis neoliberal. Madrid: Traficantes de sueño. 
- (2014). "Tras la morada oculta de Marx. Por una concepción ampliada del capitalismo”, en New Left Review, 86, pp. 57-76. Madrid: Editorial Akal.

- (2017). "El final del neoliberalismo 'progresista", en Sin Permiso, 12/01/2017, [http://www.sinpermiso.info/textos/el-final-delneoliberalismo-progresista].

Gálvez, L. (2013). "Una lectura feminista del austericidio", en Revista de Economía Crítica, 15, pp. 80-110.

Guerra Palmero, M. J. (2014). "Feminismo transnacional, globalización y derechos humanos", en Dilemata. Revista Internacional de Éticas Aplicadas, 15, pp. 161-169.

Harvey, D. (2007). Breve historia del neoliberalismo, Madrid: Akal.

- (2014). Diecisiete contradicciones y el final del capitalismo. Madrid: Traficantes de sueños.

Jaggar, A. M. (2001). "Is globalitzation Good for Women?", en Comparative Literature, 53 (4), pp. 298-314.

Maquieira, V. (2006). (Ed.), Mujeres, globalización y derechos bumanos, Madrid: Cátedra.

Shild, V. (2016). "Feminismo y neoliberalismo en América Latina", New Left Review, 96, pp. 63-79. Madrid: Editorial Akal.

Rottenberg, C. (2014). "The rise of neoliberal feminism”, Cultural Studies, 28 (3), pp. 418-437. United Kingdom: Routledge.

Streeck, W. (2017). ¿Cómo terminará el capitalismo? Ensayos sobre un sistema en decadencia. Madrid: Traficantes de sueños.

Taibo, C. (2011). "Antineoliberales, anticapitalistas", en Papeles de relaciones ecosociales y cambio social, 113, pp. 149-154.

Torres, L., Antón, E. (2010). Lo que usted debe saber sobre violencia de género, León: Obra social Caja España. 